\title{
The Intersection of Muslim Physician's Religious Beliefs and End-of-Life Care: Ethical Considerations
}

\author{
Sedigheh Ebrahimi ${ }^{1}$ and Soheil Ashkani-Esfahani ${ }^{2,{ }^{*}}$ \\ ${ }^{1}$ Medical Ethics Department, Shiraz University of Medical Sciences, Shiraz, Iran \\ ${ }^{2}$ Student Research Committee, Shiraz Medical School, Shiraz University of Medical Sciences, Shiraz, Iran \\ "Corresponding author: MD, Student Research Committee, Shiraz Medical School, Shiraz University of Medical Sciences, Karimikhan Zand St., Shiraz, Iran. Email: \\ soashkani@gmail.com
}

Received 2017 September 27; Revised 2018 December 28; Accepted 2019 January 02.

\section{Dear Editor,}

Perhaps, many physicians' minds, as well as ours, are dealing with the intellectual conflict that is euthanasia allowed when confronting an end-stage patient who is suffering from pain and discomfort and struggles not for being alive but for being relieved?

Making a decision on performing euthanasia, both active and passive, has received much attention and concern throughout the world and currently, it is being performed in several countries such as the Netherlands and Belgium $(1,2)$. At the time, end-of-life issues are among the top ten challenges of medical ethics facing public concern (3).

Muslims, due to being followers of the religion Islam, the Holy Qur'an, and the prophet, believe that taking life by any means from any kind of person in any situation but those being decided by the law is prohibited. In Holy Qur'an, it is written that "Do not take life, which Allah made sacred, other than in the course of justice" (Al-Isra, verse: 33) and "If anyone slays a person unless it is for murder or spreading mischief in the land, it would be as if he slew the whole people" (Al-Maidah, verse: 32). Moreover, Muslims believe that deciding on life and death is within the hands of Allah as Qur'an says, "When their time comes they cannot delay it for a single hour nor can they bring it forward by a single hour" (An-Nahl, verse: 61) and "And no person can ever die except by Allah's leave and at an appointed term" (Al-Imran, verse: 145). Deciding about ending the life of a terminally ill patient by her/his request is beyond his/her moral or legal obligations. The Holy Qur'an states its position on this matter in certain terms that "It is not given to any soul to die, save by the leave of God, at an appointed time" (Al-Imran, verse: 145) and "God gives life, and He makes to die" (Al-Imran, verse: 156).

Some clerics have accepted euthanasia to some extent while many Fatwas (statements from great Muslim scholars) from both Shiite and Sunni scholars forbid performing euthanasia since being contrary to "Sharia" (4). The Islamic
Code of Medical Ethics (ICME) issued in 1981 says that if the doctor scientifically believes that the patient's life cannot be restored, it is not beneficial to keep the patient alive by any heroic means like deep freezing or other methods; however, a doctor must never take a positive measure in order to end the patient's life (5).

Moreover, in many decrees of Islamic Jurisprudence, it is permitted that in patients with brain death, which is an irreversible hopeless status, we can dismiss some body organs for organ donation as a life-saving procedure after receiving permission from patient's parents or other responsible relatives in order to preserve the transplantable organs and to save another human's life $(6,7)$. Authorities have debated many factors such as brain death and the chance of organ retrieval, neurological and cardiopulmonary criteria for death, and social and ethical limits to futile interventions. Religion also takes the soul and its presence at the time of death into account, which is of a certain place of argument. These disputes have led to even greater challenges for the families and the health care professionals when they are in the place of taking decisions about desisting from life-saving medical interventions (6, 8).

According to the aforementioned points, which were a brief statement about the ideas being discussed within the Muslim society, we assume that consistent with the Islamic beliefs, playing any role in ending a human's life shall be prohibited; however, saving a life by any means possible in a medically and logically hopeless end-stage patient not only should have no ethical approval but also can end up with loss of budget, medicine, and equipment, which could save another person's life. We assume that if a miracle is going to happen, it does not need us to prolong the torment of the patient by any means possible, and it will happen in the proper timing. It is maybe better to do what we can to reduce the pain and discomfort in these patients and let "Allah" decides "A person dies when it is writ- 
ten" (Al-Imran, verse: 185).

We may call it "physician-decided euthanasia" in which we do all we can to cure the patient or at least reduce the pain, regardless of the patients will for ending his/her life; but when it comes to cardiorespiratory arrest and we scientifically know that if we perform the resuscitation even if the patient comes back there is no hope for being cured and the scenario will be repeated again, we may decide not to do it. However, since Islam gives the permission to the patient's family and near relatives to decide for him/her at the times he/she cannot decide, we believe if they want us to perform the resuscitation, we cannot ignore it. Every effort should be made to protect human's life since the life of a human is not something that a person or his relatives or others can decide on ending it.

In the end, we invite health professionals, particularly in Islamic health care systems, to share their knowledge and thoughts in the case of the end of life in medically hopeless end-stage patients in order to reach a unity or at least an ethical protocol in this regard.

\section{Footnotes}

Conflict of Interests: None declared. Funding/Support: None declared.

\section{References}

1. van der Maas PJ, van der Wal G, Haverkate I, de Graaff CL, Kester JG, Onwuteaka-Philipsen BD, et al. Euthanasia, physician-assisted suicide, and other medical practices involving the end of life in the Netherlands, 1990-1995. N Engl J Med. 1996;335(22):1699-705. doi: 10.1056/NEJM199611283352227. [PubMed: 8929370].

2. Burton B. Australia turns to drug company representatives to cut prescribing. BMJ. 2002;324(7348):1234. [PubMed: 12028968]. [PubMed Central: PMC1123208].

3. Breslin JM, MacRae SK, Bell J, Singer PA; University of Toronto Joint Centre for Bioethics Clinical Ethics Group. Top 10 health care ethics challenges facing the public: Views of Toronto bioethicists. BMC Med Ethics. 2005;6. E5. doi: 10.1186/1472-6939-6-5. [PubMed: 15978136]. [PubMed Central: PMC1180442].

4. Aramesh K, Shadi H. Euthanasia: An Islamic ethical perspective. Iran J Allergy Asthma Immunol. 2007;6(Suppl. 5):35-8.

5. Cruess SR, Cruess RL, Steinert Y. Role modelling-making the most of a powerful teaching strategy. BMJ. 2008;336(7646):718-21. doi: 10.1136/bmj.39503.757847.BE. [PubMed: 18369229]. [PubMed Central: PMC2276302].

6. Sachedina A. Islamic biomedical ethics principles and application. Oxford Scholarship Online; 2009. doi: 10.1093/acprof:oso/9780195378504.001.0001.

7. Bulow HH, Sprung CL, Reinhart K, Prayag S, Du B, Armaganidis A, et al. The world's major religions' points of view on end-of-life decisions in the intensive care unit. Intensive Care Med. 2008;34(3):423-30. doi: 10.1007/s00134-007-0973-8. [PubMed: 18157484].

8. Khater WA, Akhu-Zaheya LM, Abu Alhijaa EH, Abdulelah HA, El-Otti SN The practice of withholding and withdrawing life-support measures among patients with cancer in Jordan. Int J Palliat Nurs. 2011;17(9):4405. doi: 10.12968/ijpn.2011.17.9.440. [PubMed: 22067735]. 